\title{
Categories to Assess the Understanding of University Students about a Mathematical Concept
}

\author{
Flor Monserrat Rodríguez-Vásquez iDa \\ Jhonatan Andres Arenas-Peñaloza iD b \\ ${ }^{a}$ Universidad Autónoma de Guerrero, Facultad de Matemáticas. Posgrado en Educación Matemática, \\ Chilpancingo, México \\ ${ }^{\mathrm{b}}$ Universidad de la Costa CUC, Departamento de Ciencias Naturales y Exactas, Barranquilla, Colombia
}

Received for publication on 29 May 2020. Accepted after review on 11 Nov. 2020

Designated editor: Claudia Lisete Oliveira Groenwald

\begin{abstract}
Background: One of the problems in mathematics education is students' little understanding of mathematics both at the basic and higher educational levels, which is why we consider essential the design of adequate instruments and methods that can measure understanding about specific concepts. Objective: To assess the understanding of university students of the concept of a real function. Design: The research is qualitative as the attributes of a cognitive construct were analysed and interpreted. Setting and participants: There were 36 students of a degree in mathematics (18-20 years old) whose productions were analysed. All the students had taken the Calculus I course. Data collection and analysis: A test of six items related to tasks that involved the concept of function was applied, the data analysis was carried out from the evaluation categories proposed by Albert and Kim, who consider three categories to assess understanding, those being: the ability to justify, to understand why a particular mathematical statement is true, and to understand where a mathematical rule comes from. Results: The evaluation of the understanding of the concept of function has shown that, in order to achieve a high understanding, not only skills must be developed for the recognition of aspects of the function such as its definition, its discrimination or its application, but the ability to be able to justify such aspects must be considered too. Conclusion: The categories of understanding considered help to strengthen conceptual and procedural understanding, indicating comprehensive understanding.
\end{abstract}

Keywords: Understanding; evaluation categories; actual function; Mathematics education.

\section{Categorías para Evaluar la Comprensión de Estudiantes Universitarios sobre un Concepto Matemático}

Autor de correspondencia: Flor Monserrat Rodríguez Vásquez. Email: flor.rodriguez@uagro.mx 


\section{RESUMO}

Contexto: Una de las problemáticas en educación matemática, es la endeble comprensión en matemáticas que tienen los estudiantes, tanto en el nivel educativo básico como en el superior, por lo que consideramos fundamental el diseño de instrumentos y métodos adecuados que puedan medir la comprensión sobre conceptos específicos. Objetivo: Evaluar la comprensión de estudiantes universitarios sobre el concepto de función real. Diseño: La investigación es cualitativa, debido a que se analizaron e interpretaron los atributos sobre un constructo cognitivo. Escenario y participantes: Fueron 36 estudiantes de una licenciatura en matemáticas (18-20 años) de quienes se analizaron sus producciones, todos habían llevado el primer curso de cálculo. Colección y análisis de datos: Se aplicó un test de seis ítems relativos a tareas que involucraron el concepto de función, el análisis de datos se realizó desde las categorías de evaluación propuestas por Albert y Kim, quienes consideran tres categorías para evaluar la comprensión, a saber, la habilidad para justificar, entender por qué una afirmación matemática particular es verdadera y, entender de dónde viene una regla matemática. Resultados: La evaluación sobre la comprensión del concepto función, ha evidenciado que, para alcanzar una comprensión alta se deben desarrollar no solo habilidades para el reconocimiento de aspectos de la función como su definición, su discriminación o su aplicación, sino además considerar la habilidad para poder justificar tales aspectos. Conclusión: Las categorías de comprensión consideradas, ayudan en el fortalecimiento del entendimiento conceptual y procedimental indicando una comprensión integral.

Palabras clave: Comprensión; categorías de evaluación; función real; Educación Matemática.

\section{INTRODUCTION}

The understanding of a mathematical concept is a topic that has gained wide participation in the research carried out in mathematics education. To this end, different theoretical frameworks that address this line of research have been implemented (e.g., Skemp, 1980; Sierpinska, 1990; Pirie \& Kieren, 1994; Kastberg, 2002; Arnon et al., 2014; Albert \& Kim, 2015), which show the characterisation of understanding from each of their perspectives, their similarities and their differences, but all with a common objective, to measure or assess the mathematical understanding of students. And in some cases, it is proposed to establish categories to design activities or items that can help teachers when evaluating the mathematical understanding of their students. 
According to Schoenfeld (2007), a teachers' common goal should be students' understanding of concepts. In this sense, especially in mathematics, the understanding of concepts is an objective for its teaching and learning.

The understanding of mathematics has been studied since the 1970s. Skemp (1976) identified two types of understanding: relational understanding as "knowing both what to do and why" (p. 2) and instrumental understanding as "rules without reasons" (p. 2). Michener (1978) pointed out that understanding mathematics is a complementary process for problem solving, where the process is concerned with building and enriching a knowledge base, and this includes creating connections of various types, as well as elements (examples, results and concepts). Sierpinska (1990) proposed understanding as an act, but an act involved in a process of interpretation, this interpretation being a developing dialectic between conjectures and increasingly elaborate validations.

Nickerson (1985) identified some characteristics of what understanding is, including being able to visualise the deeper properties of a concept, to find specific information in a situation more quickly, to be able to represent situations, and to visualise a situation using mental models. Nickerson stressed that the more you know about a topic, the better you understand it, thus showing the relationship between knowledge and understanding. For their part, Hiebert and Carpenter (1992) emphasised that the level of understanding is determined by the number and strength of its connections, connections between mathematical ideas, procedures, or facts. In addition, Wilkerson and Wilensky (2011) cited three aspects about the resources and processes for mathematical understanding: mathematical knowledge as a network, the role of different resources in learning, and learning as the construction of connections. They also point out that researchers interested in the flexible and adaptive nature of mathematical understanding describe the structure of mathematical knowledge as a network of relationships between different properties, objects and procedures that influence a given mathematical idea.

Now, regarding the function concept, this is one of the fundamental concepts in mathematics, however, despite being in the backbone of mathematics, it is one of the most difficult concepts to master in school mathematics, which is partly a consequence of the various sub-notions associated with the concept, since even at basic levels, the functions can be 
approached from different contexts, so that difficulties arise from an early age. Likewise, Díaz (2013) mentions that the concept of function is one for which students have problems developing a satisfactory understanding, in addition to the fact that the difficulties that students present seem to focus on its complexity and generality. The notion of function is acquired from the first years of life, however, as a formal object in the teaching of mathematics, the concept of function is taught from the secondary educational level to the university level (National Council of Teachers of Mathematics, 2000; Secretaría de Educación Pública, 2011). This concept is characterised by its abstract nature and is considered prior knowledge in subjects such as differential and integral calculus, linear algebra, abstract algebra, and mathematical analysis (Farfán \& García, 2005). Also, functions are used to model phenomena in areas such as physics, chemistry, biology, social sciences, and economics.

Additionally, research carried out on the teaching and learning processes of the concept of function report that there are different difficulties related to its learning. For example, Ortega and Pecharromán (2014) mention that students show errors in learning the global properties of functions; Amaya and Sgreccia (2014) and Díaz, Haye, Montenegro, and Córdoba (2015) report difficulties associated with carrying out transformations and articulations between the representations of a function; and more recently, Cuevas and Pluvinage (2017) report that the difficulties that students manifest about the concept of function focus on the formality and rigor of the definition. On the other hand, Watson and Harel (2013) allude to the fact that mathematics teachers induce difficulties when they themselves do not have a good mathematical knowledge of the concept of function.

Several inconsistent conceptions that students present about the concept of function in the classroom are generated because the understanding of the concept and its meanings is not prioritised, as both teachers and students are limited to algebraic manipulation of this concept, which restricts its understanding (Prada, Hernández, \& Ramírez, 2014). As mentioned by Flores, Neira, Carrillo, and Peñaloza (2019), the teaching of the concept of function focuses on prioritising the algebraic register, leaving aside both the graphic and tabular registers. In other words, the way to better understand a mathematical object is by coordinating its different representations. 
Some investigations that have focused on studying the concept of function from different perspectives (Vinner \& Dreyfus, 1989; Crespo \& Ponteville, 2003; Serrano, 2007; Silva \& Kaiber, 2013; Figueiredo \& Contreras, 2013) have revealed the need for research focused on understanding this concept, due to its impact on the curriculum and other disciplines; as well as the need to address the difficulties that literature reports in its teaching and learning processes. In particular, Bardini, Pierce, Vincent, and King (2014) conducted a study on the understanding of university students about the concept of function, emphasizing that it is important to constantly reinforce old concepts in new environments, helping to establish connections between related mathematical ideas, since understanding is affected by beliefs and misconceptions. They even mention that if students go through school with misconceptions or without deep understanding, it can be a difficult situation to revert. Also, they emphasise that students should be exposed to many examples where representations are linked, and then synthesise and formalise their learning through the application of the concept of function. Finally, Bardini et al. (2014) point out that it is essential for students to be aware of the aspects of the definition of the function, and to be able to establish connections between different representations of the concept of function.

For his part, Díaz (2013), also mentions some crucial aspects for a deep understanding of the function concept, among them, the interpretation of functions represented by graphs, the description of situations, formulas and a table, i.e., that situations of the real world be modelled, transference between the multiple representations of functions, besides encouraging the student to be able to use it in non-mathematical fields and carry out tasks of transformation and conversion of representations between at least two representation systems.

However, we think that although it is essential to know the factors that cause little understanding, specific frames of reference should be structured that allow students to assess the understanding of the concepts and help the teacher to redesign activities to improve said understanding accordingly.

For this research, we used the reference framework of Albert and Kim (2015), as it is based on the curricular design proposed by the Common Core State Standards for Mathematics (CCSSM), aiming that teachers assess the mathematical understanding of their students. In this sense, the objective of this article is to analyse the understanding of university students about the concept 
of function to contribute to the improvement of the teaching and learning processes of said concept. For this, we designed assessment items that made it possible to measure the students' level of understanding of the concept of real function. From the interpretation of the levels of understanding, we can not only identify the difficulties about the very understanding but propose concrete tasks to increase the comprehension levels.

\section{Theoretical Foundations}

Like many mathematical concepts, function is a part of the basic knowledge that everyone must understand to communicate and interact in society (Amaya, Pino-Fan \& Medina, 2016). In this sense, Bardini et al. (2014) mention that the notion of function is a unifying concept not only within the context of mathematics itself, but also between mathematics and the real world.

In the historical development of the function concept, it is undoubtedly an ally to understand it as a unifier. The Greek, for example, since ancient times used verbal or graphic representations that today refer to the concept of function, and that they were unaware of at the time. Historically, Díaz (2013) mentions three significant periods in the development of the function concept: the ancient times, when the dependence between quantities and different magnitudes can be identified, although the notions of variable quantity and function are not isolated; the middle ages, when development of the concept is divided into two parts, the non-Latin and the Latin. In the first part (years 500 to 1200), although solutions of equations were found, the idea of variable did not arise and therefore the functional idea between two variables neither. In the second (from the 13th century on), when a primitive theory of functions was achieved but the functional correspondence could not yet be expressed in an algebraic language and, finally, the modern period, in which four stages are identified and, correspondingly, four function definitions given by Euler, Fourier, Dirichlet, and Bourbaki respectively, and in which the evolution of their constructs is observed.

Pino-Fan, Parra-Urrea, and Castro-Gordillo (2019) perceive the concept of function as a fundamental component in the historical development of humanity and that, throughout its evolution, at least six interpretations have been adopted: the function as correspondence, where the concept is established as the association of elements between two sets; the function as a relationship 
between variable quantities, seen from the field of physics, from which the notion of dependent and independent variable quantities was established; the function as a graphical representation, established through the need to represent the variation relationship between physical quantities; function as an analytical expression, a conceptual formalisation that began to be established through the relationship of analytical expressions; the function as arbitrary correspondence, where the correspondence rule between variables was generalised. Finally, the function from set theory, where the formal definition of the concept is established, expressed as follows:

"Definition: A relation where each element of a set A corresponds to a single element of a set $B$, it is called a function of $A$ in B." (Arizmendi, Carrillo, \& Lara, 2003, p. 40).

However, the traditional teaching of the concept has been limited to establishing only the dependency relationship between the variables, leaving aside the formal definition, isolating the connection between the definitions of domain, codomain and path (Pino-Fan, Parra-Urrea, \& Castro-Gordillo, 2019), although Amaya, Pino-Fan, and Medina (2016) mention that during the teaching-learning process of the concept, the most used records are the analytical algebraic, numerical, graphic and tabular records.

Now, understanding in mathematics is a subject widely studied in mathematics education, for example, from different theoretical frameworks (e.g., Skemp, 1980; Vinner, 1983; Dreyfus \& Eisenberg, 1982; Sfard, 1989; Sierpinska, 1990, 1992 ; Pirie \& Kieren, 1994; Kastberg, 2002; Albert \& Kim, 2015 ) and it is characterised from each of its focuses, their similarities and their differences. However, since our interest is to assess understanding from a model, in which categories are established for the design of activities or items, we use the theoretical framework to analyse evaluation items, exposed by Albert and Kim (2015), which is based on the definition of understanding of the CCSSM, who textually indicate that: "One hallmark of mathematical understanding is the ability to justify, in a way appropriate to the student's mathematical maturity, why a particular mathematical statement is true or where a mathematical rule comes from..." (NGA Center \& CCSSO, 2010, p. 4). In this sense, mathematical understanding consists of three categories: the ability to justify, to understand why a particular math statement is true, and to understand where a mathematical rule comes from. Under these three 
categories, the theoretical framework to analyse and organise the evaluation items is provided. Each of the categories is described below.

The ability to justify. In this category, students must know how to support their conclusions to communicate their processes in the resolution of items and to build quality justifications, that is, provide solid reasons for their own conclusion. Therefore, students are expected to give good mathematical justifications, in other words, that their justifications be influenced by their mathematical reasoning, their ability to construct mathematical conjectures, develop and evaluate mathematical arguments, and select and use different types of representations. Albert and Kim (2015) show an example of this category: they suppose that the student is asked to solve the problem $2+2$, then if the student only has procedural skills, he/she could answer that the sum is 4 without providing adequate justifications, but if the student has knowledge of related concepts, for example, the concept of number including continuous and discrete quantities, and knows different representations, then he/she could justify his/her process to solve the problem in different ways.

Understand why a particular mathematical statement is true. Students are expected to identify and argue whether a statement is true or false, depending on the contextual situation of the statement. For example, the statement "three multiplied by any number always increases" could be true or false, depending on the set to which that number belongs, i.e., the statement is true under specific conditions, for example, if 3 is multiplied by a number bigger than 1, the statement is true, but if it is multiplied by numbers that are between 0 and 1 , the statement is false. Then, students must understand under what conditions the statement is true or not by giving counterexamples.

Understand where a mathematical rule comes from. According to the CCSSM (NGA Center and CCSSO, 2010), students who can explain a mathematical rule understand that mathematics and are more likely to be successful in less familiar tasks. Albert and Kim (2015) give the example of when they are asked to solve the division between fractions $2 / 5$ and $14 / 15$, then they mention that students who know the mathematical rule for the division of fractions could find the answer based on procedural skills, but it could be just a memorisation procedure, in other words, when students demonstrate only procedural or process memorization skills, they may not understand the use of the rule. However, when students understand where this rule comes from, i.e., 
In other words, they must understand that the new fraction that is formed has as its numerator a fraction $(\mathrm{a} / \mathrm{b})$ and as its denominator another fraction $(\mathrm{c} / \mathrm{d})$, and this new fraction must be multiplied both in numerator and denominator by the inverse multiplicative of the denominator of the new fraction formed by the division, i.e., by $\mathrm{d} / \mathrm{c}$, from which it follows that dividing $\mathrm{a} / \mathrm{b}$ by $\mathrm{c} / \mathrm{d}$ is equivalent to multiplying the fractions $\mathrm{a} / \mathrm{b}$ and $\mathrm{d} / \mathrm{c}$, , then they could solve the problem in a different way, showing that they understood the concept of dividing fractions.

Finally, it is worth mentioning that one of the main purposes of this theoretical framework to analyse assessment items is to illustrate how understanding informs teaching practices and serves as a catalyst to help teachers develop measurement tasks that represent the student's mathematical learning. In addition, teachers are encouraged to improve their teaching methods so that they are more effective, since they know the understanding processes of their students (Codes, Delgado, Gonzalez, \& Monterrubio, 2013).

\section{METHODOLOGY}

The research follows a descriptive methodology (Dankhe, 1986), since the specificity of the characteristics of the understanding of a concept is sought and these are assessed from the scope achieved according to the success of the students when solving mathematical problems. To do this, a test comprising six items was designed and these phases were followed:

- Phase 1. Item design. This phase was developed in four stages. In the first, the Albert and Kim (2015) frame of reference was analysed, and based on this, 6 items were designed, 2 for each category of understanding of the frame of reference. For category 1 (the ability to justify), items 3 and 4 correspond; for category 2 (understanding why a particular mathematical statement is true), items 2 and 5; and items 1 and 6 , to category 3 (understand where a mathematical rule comes from). In the second stage, experts carried out a validation, in which each of the items were solved, and after the validation, the items were redesigned. In the third, users carry out a validation. Five students who were in the second semester of the teaching degree in mathematics (licenciatura) participated. As a result of this validation, new modifications were made to the items. Finally, in the fourth stage, a validation was again carried out by an expert who has more than ten years' experience as a mathematics teacher at the Universidad Autónoma de Guerrero (Autonomous 
University of Guerrero). Thus, the final design of the 6 items was obtained (see annex).

Phase 2. Application of the items. Once the validation by users and experts was carried out, the items were applied. The application time was thirty minutes. The students were coded with the letter A and the number corresponding to the order of delivery of their answers. That is, A1 means the first student to deliver the solution to the six items.

Phase 3. Evaluation of the responses to the items. For the evaluation of the six items applied, the Albert and Kim frame of reference was considered. This phase was developed in three stages. In the first, evaluation criteria were specified for the items (see Table 1) in relation to the understanding categories and the possible responses of the students. In the second stage, the responses of each student were compared in relation to these criteria. Finally, in the third stage, an analysis of the responses given by the students was carried out.

\section{Table 1}

Evaluation criteria in relation to the categories of understanding

\begin{tabular}{|c|c|c|c|}
\hline Items & $\begin{array}{l}\text { Criterion } 1 \\
\text { (Low) }\end{array}$ & $\begin{array}{l}\text { Criterion } 2 \\
\text { (Medium) }\end{array}$ & $\begin{array}{l}\text { Criterion } 3 \\
\text { (High) }\end{array}$ \\
\hline 1 & $\begin{array}{l}\text { The student does } \\
\text { not recognise the } \\
\text { criterion of the } \\
\text { vertical line to } \\
\text { determine if a } \\
\text { graphical } \\
\text { representation is a } \\
\text { function. }\end{array}$ & $\begin{array}{l}\text { The student } \\
\text { recognises the } \\
\text { criterion of the } \\
\text { vertical line to } \\
\text { determine if a } \\
\text { graphical } \\
\text { representation is a } \\
\text { function, however, } \\
\text { the justification is } \\
\text { not in accordance } \\
\text { with the one-to-one } \\
\text { correspondence. }\end{array}$ & $\begin{array}{l}\text { The student uses the } \\
\text { criterion of the } \\
\text { vertical line } \\
\text { correctly to } \\
\text { determine if a } \\
\text { graphical } \\
\text { representation is a } \\
\text { function. In } \\
\text { addition, his } \\
\text { arguments show the } \\
\text { understanding of the } \\
\text { relationship, that an } \\
\text { element of the } \\
\text { domain corresponds }\end{array}$ \\
\hline
\end{tabular}


to a single element in the codomain.

2

3

4
The student does not provide an opinion on the statement or the opinion is incorrect.

The student identifies the truth value of the statement; however, his/her arguments do not validate his/her opinion.

The student does not identify which graphical representations

represent a

function.
The student does not perform any type of classification in relation to the type of function.
The student identifies which graphical representations are functions.

However, he/she does not provide solid reasons in his conclusion.

The student manages to classify some functions, but his/her justification is insufficient to validate his classification.
The student identifies the truth value of the statement and his/her arguments correctly validate his opinion.

The student identifies which graphical representations are functions and provides solid reasons to validate his conclusion.

The student correctly classifies the functions according to their characteristics and provides solid reasons to validate his conclusion. 


\begin{tabular}{lll}
\hline $\begin{array}{l}\text { The student does } \\
\text { not issue any } \\
\text { argument to } \\
\text { validate the claim. }\end{array}$ & $\begin{array}{l}\text { The student } \\
\text { generates some } \\
\text { arguments, but } \\
\text { they are not } \\
\text { enough to justify } \\
\text { the validity of the } \\
\text { claim. }\end{array}$ & $\begin{array}{l}\text { The student } \\
\text { generates the } \\
\text { necessary arguments } \\
\text { to justify that the } \\
\text { statement is true. }\end{array}$ \\
$\begin{array}{ll}\text { The student } \\
\text { The student does } \\
\text { criteria by which } \\
\text { two functions are } \\
\text { equal. }\end{array}$ & $\begin{array}{l}\text { recognises the } \\
\text { criteria (at least } \\
\text { one) by which two } \\
\text { functions are equal. }\end{array}$ & $\begin{array}{l}\text { The student } \\
\text { recognises the } \\
\text { criteria by which } \\
\text { two functions are } \\
\text { equal. Furthermore, } \\
\text { his/her arguments } \\
\text { reveal the } \\
\text { justification is not } \\
\text { commensurate with } \\
\text { the situation. }\end{array}$ \\
& $\begin{array}{l}\text { understanding of } \\
\text { why both functions } \\
\text { are equal. }\end{array}$ \\
\end{tabular}

The test was applied to 36 students (18-20 years old) of the first year of the teaching degree in mathematics at the Universidad Autónoma de Guerrero, Mexico. The selection criterion was that the students had taken the subject Calculus I, since it teaches the concept of function, as well as its applications. Likewise, the objective of the research was indicated, and it was pointed out that participation was voluntary, ensuring the anonymous reliability of the participants, in accordance with the University's Code of Ethics. ${ }^{1}$

\section{RESULTS AND ANALYSIS}

Following, the results obtained are presented based on the evaluation of the students' responses considering the criteria established in Table 1.

\footnotetext{
${ }^{1}$ Acta Scientiae is exonerated from any consequence or resulting damage to any of the participants of the items, according to Resolution No. 510, of April 7, 2016, of the Consejo Junta Nacional de Salud (National Board of Health Council).
} 
Likewise, the evaluation made it possible to classify the understanding shown by the students in terms of each category, as can be seen in Table 2.

\section{Table 2}

Students' understanding in relation to each category.

\begin{tabular}{lcccr}
\hline \multicolumn{1}{c}{ Categories } & $\begin{array}{c}\text { Reviewe } \\
\text { d item }\end{array}$ & $\begin{array}{c}\text { With low } \\
\text { understand } \\
\text { ing }\end{array}$ & $\begin{array}{c}\text { With } \\
\text { medium } \\
\text { understand } \\
\text { ing }\end{array}$ & $\begin{array}{c}\text { With high } \\
\text { understandin } \\
\text { g }\end{array}$ \\
\hline & 3 & 16 & 8 & 12 \\
Ability to justify & 4 & 16 & 14 & 6 \\
$\begin{array}{l}\text { Understand why } \\
\begin{array}{l}\text { a mathematical } \\
\text { statement is true }\end{array}\end{array}$ & 2 & 9 & 16 & 11 \\
$\begin{array}{l}\text { Understand } \\
\text { where a }\end{array}$ & 5 & 12 & 14 & 10 \\
$\begin{array}{l}\text { mathematical } \\
\text { rule comes from }\end{array}$ & 6 & 24 & 1 & 11 \\
\hline
\end{tabular}

To better organise and describe the work done by students, the analysis is presented in relation to the three categories of understanding.

\section{Ability to justify}

For this category of understanding, students' responses to items 3 and 4 were assessed. Regarding item 3, it was evidenced that 12 students, that is, $33 \%$ achieved a high understanding of it, since they identified which graphical representations correspond to a function and also managed to generate solid reasons and arguments to validate their answers, while 8 students $(22 \%)$ only managed to identify which of the graphical representations given correspond to 
a function. Finally, 16 students (45\%) showed low understanding, for they did not identify which graphical representations represent a function.

For item 4, it was evidenced that 16 students (44\%) failed to perform some type of classification in relation to the types of function, showing difficulties in relating their characteristics to classify them. According to the theoretical frame of reference, the students failed to provide solid reasons for constructing conjectures and evaluating mathematical arguments. Also, it is evident that 14 students (39\%) managed to classify some functions, but at the time of justifying their classification they did not provide sufficient arguments to validate their answers. However, 6 students (17\%) correctly classified the functions and, in addition, managed to give solid reasons to validate their conclusions.

In this first category, the result obtained was that most of the students presented a low understanding of it. When placing both items (3 and 4) in correlation, we could verify that only $25 \%([(12+6) * 100] / 72)$ of the students could justify them. Compared to what is mentioned by the Common Core State Standards for Mathematics (2010), we can say that university students do not understand efficiently, for they could not use properties established in the concept of function to generate solid arguments in relation to the development of their mathematical processes, neither could they to criticise the reasoning of their other colleagues.

For example, on item 3, student A6 showed a high understanding in this category, since he correctly used the criterion of the vertical line to determine if a graphical representation is a function and his arguments expressed his understanding of the correspondence of the rule and of a characteristic of the concept of function, specifically that each element of the domain corresponds to a single element in the codomain (see Figure 1). 


\section{Figure 1}

Response of A6 for category 1 (item 3)

3. En las siguientes representaciones gráficas, determine cuáles representan una función real de variable real. Explique ampliamente porqué.

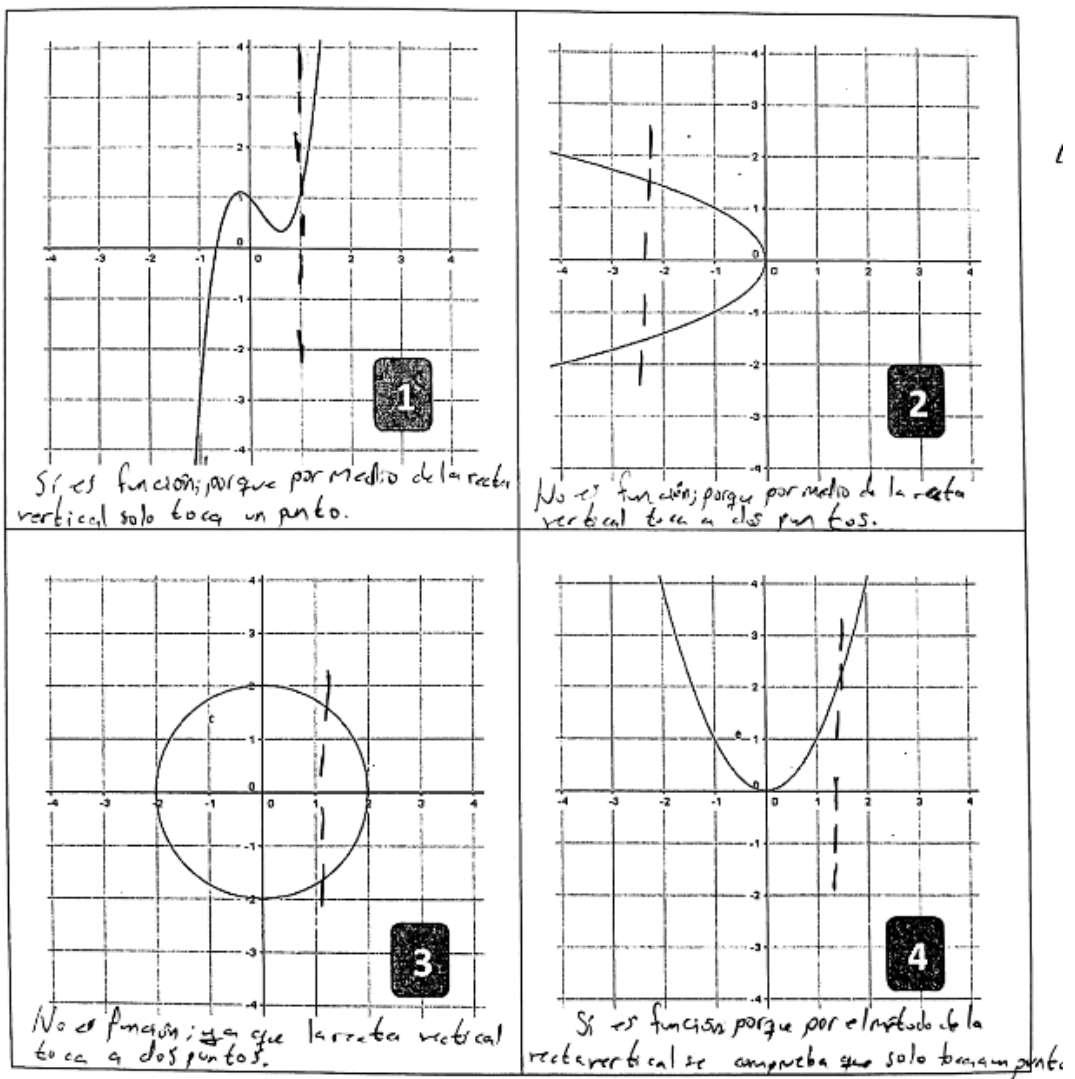

Another argument to justify a high understanding in this category was evidenced in the answer given by A22 (Figure 2), in which the student manifests a condition to determine when a graphical representation is or is not a function. He also recognised the characteristic of the concept of function, that each element of the domain corresponds to a single element in the codomain, 
by means of a verbal representation. Specifically, A22 evaluates at specific points to generalise that every element of $x$ corresponds to a single element of $y$, in the representations that are functions. And for representations that are not functions, he uses the same criterion by giving examples where it does not happen.

\section{Figure 2.}

Response of A22 for category 1 (item 3)

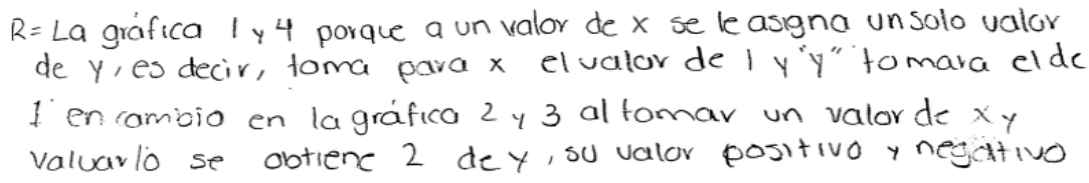

On the other hand, a case that represents medium understanding, that is, the category that emphasises that the student identifies which graphical representations are functions, but does not provide solid reasons in his conclusion, is that of A17. His arguments are insufficient to justify the answer to item 3 (see Figure 3), for A17 does not show knowledge about the characteristic of correspondence of the uniqueness of the domain variables with the codomain. Limiting his answer to associating the graphical representations to their algebraic representations, which correspond to specific functions.

\section{Figure 3}

Response of A17 for category 1 (item 3)

$$
\begin{aligned}
& \text { Serian } 1 \text { y } 4 . \\
& \text { Siendo } x \in \mathbb{R} \Rightarrow f(x)=x^{2} \\
& \qquad f(x)=x^{3} \\
& \therefore x^{2} y x^{3} \in \mathbb{R} .
\end{aligned}
$$




\section{Understanding why a particular mathematical statement is true}

In this category, the students' responses to items 2 and 5 were evaluated. In relation to item 2 , we see that 9 students (25\%) showed a low understanding, since they did not emit a truth value on the item's statement, or the truth value emitted was incorrect. However, 16 students (45\%) gave the truth value correctly, but their arguments did not validate their opinion. Also, it is evidenced that 11 students (30\%) managed to emit a correct truth value and their arguments were sufficient to validate their opinion, showing a high understanding.

Regarding item 5, we can see that 10 students (28\%) presented a high understanding in their answers, for they managed to generate the necessary arguments to justify that the statement issued was true. Likewise, 14 students (39\%) presented some arguments in their answers to justify the validity of the statement, but not enough to support their position. Finally, 12 students (33\%) failed to issue arguments to validate or refute the claim.

When comparing the results obtained from both items ( 2 and 5) in this category, we can affirm that $42 \%([(16+14) * 100] / 72)$ of the students' answers evidence that the relative majority shows a medium understanding when figuring out why a particular mathematical statement is true, while $29 \%$ of the students are at the low level and $29 \%$ at the high level for this category. In relation to what is mentioned by the Common Core State Standards for Mathematics (2010), we can affirm that few university students made conjectures about their process to explore their veracity, conducting inductive reasoning according to the context of the information provided by the problem situation (items).

For example, on item 2, student A19 shows a high understanding, since he emitted a correct truth value and, in addition, in his justification there are arguments that validate his position in relation to the statement made. It is observed that the student identifies the dependent variable (height) and the independent variable (age) relating them as a function. Likewise, he refers to the behaviour of the function that could model the situation, discarding that it is constant, although it is always increasing (see Figure 4). 


\section{Figure 4}

Response from A19 for category 2 (item 2)

2. Considere el siguiente enunciado: "el crecimiento de un niño puede ser modelado por una función real de variable real". La afirmación anterior es verdadera o falsa. Justifique ampliamente su respuesta.

Es verdadera por g' cuando un niño crece sepuede tomar suedad. y su estatura para tomarla como $x$ e $y$, asi se puede tener una funcion que aunque no sea constante Siempre va hacia arriba.y siempre sera una variable real.

Also, in item 2, student A23 is part of the $42 \%$ of students who have a medium understanding because the truth value emitted is correct, but his arguments are insufficient to validate his answer (see Figure 5). It was observed that A23 failed to explain in detail the variables involved in the situation and how they behave, for example, failing to express dependence between the two variables involved.

\section{Figure 5}

Response from A23 for category 2 (item 2)

Verdadera, forque se puede realizar

una tabla en donde se ponga los datos de coda vet que crece el niño y después se puede presentor graficamente. 
Regarding the low level of understanding, in the same item 2, A20 emitted an incorrect truth value and his arguments were not in accordance with the situation. A20 expressed that the given statement was false and furthermore did not relate the variables of the function that could have modelled the situation. For example, he stated that there is no dependence between a child's growth and elapsed time (see Figure 6).

\section{Figure 6.}

Response from A20 for category 2 (item 2)

2. Considere el siguiente enunciado: "el crecimiento de un niño puede ser modelado por una función real de variable real". La afirmación anterior es verdadera o falsa. Justifique ampliamente su respuesta. ampliamente su respuesta.
Tepresentar como una funsión real, el crecimiento no depende del tiempo ni la edad, asi como Tampoco para ello no se puede representar o mode lario como una funcrón real de Varrable real

\section{Understanding where a mathematical rule comes from}

To analyse this last category, the responses given by the students to items 1 and 6 were reviewed. Regarding item 1, it is evidenced that 24 students $(67 \%)$ have a low understanding, for they do not show an understanding when using the criterion of the vertical line to determine if a graphic representation corresponds to a function. Only 1 student $(3 \%)$ managed to recognise the usefulness of the vertical line criterion, however, the justification for its use was not consistent with the characteristics of the mathematical rule. Likewise, 11 students (30\%) recognised the usefulness of the criterion and their arguments show that they understand the mathematical rule which establishes that an element of the domain corresponds to a single element in the codomain.

Item 6 revealed that 12 students $(33 \%)$ did not understand why two functions are equal. Although 21 students (58\%) managed to recognise at least one criterion to determine when two functions are equal, their justifications 
were not consistent. Only 3 students $(8 \%)$ recognised the criteria by which two functions are equal, and the arguments presented demonstrate it.

In this last category, $50 \%$ of the students' responses show a low level of understanding. When placing both items (1 and 6) in correlation, we can see that students do not understand where a mathematical rule comes from, both in its use as in its existence. Therefore, university students did not consider what are the necessary tools to solve a mathematical problem, or they could not establish, or at least identify, a pattern or algebraic structure. Consequently, it was difficult for them to apply mathematical concepts to solve problems that arise in everyday life (CCSSM, 2010).

For example, for item 1, the answer given by $\mathrm{A} 3$ showed that he understands where a mathematical rule comes from, since he manages to explain when and how to use the criterion of the vertical line to determine whether or not a graphical representation is a function. A3 expresses that for a graphical representation to correspond to a function, the line must only cut it once, which indicates that each element of the domain corresponds to a single element in the codomain. In addition, he expresses that if the vertical line touches the graphical representation twice, we would be talking about a relationship and not a function (see Figure 7). 


\section{Figure 7}

A3 response for category 3 (item 1)

1. En una representación gráfica, el criterio de la recta vertical nos ayuda a determinar si ésta corresponde o no a la representación de una función. Explique ampliamente porqué es suficiente utilizar este criterio para validar esta afirmación.

Porque al trazarse una recta a cualquier grática el número de veces que esta recta corte determinará sies una función, si la corta una sola vez es tunción, sino es una relación. Se considera una función cuando al cortarse uno ónicavez dá un resultado 'a cada elemento de " le correspande uno y sób uno de $y^{\prime \prime}$

Another argument to justify a high understanding in this category was evidenced in the answer given by A6 (Figure 8). We observed that this student managed to relate the criterion of the vertical line with a characteristic of the definition of the concept of function. Through the Venn diagram, he exemplified the correspondence relationship that to each domain value corresponds a single element of the codomain. Also, he showed evidence of this relationship, with the use of the criterion of the vertical line, when it comes 
to determining whether a graphic representation is a function, through graphicverbal examples.

\section{Figure 8}

A6 response for category 3 (item 1)

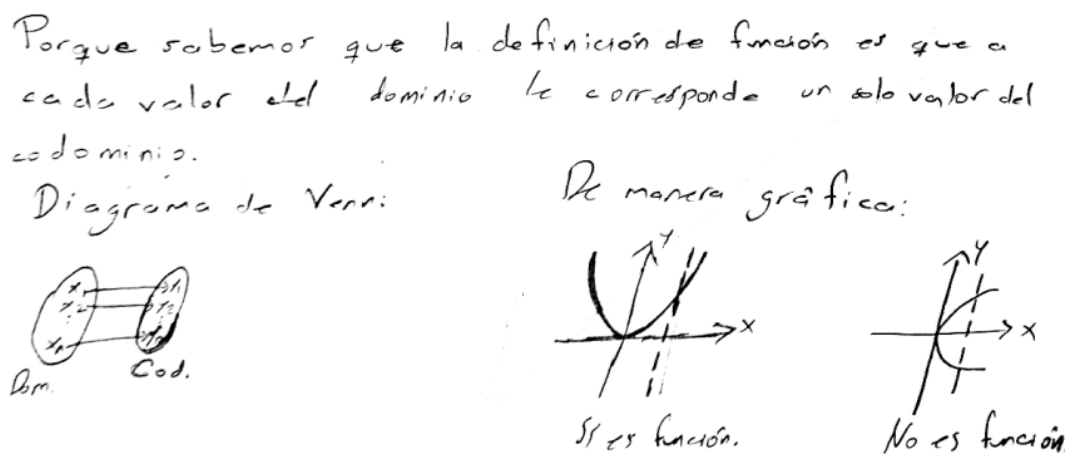

For item 6, a response that justifies a high understanding in this category was evidenced in the answer given by A24 (Figure 9), in which the student understands that for two functions to be equal, their domains and correspondence rule must be the same. This is observed when the student gives evidence through an algorithmic process of the equality of the rules of correspondence and regarding the domain of both functions, he identifies that they have the same output set. 


\section{Figure 9}

A6 response for category 3 (item 1)

6. Considérese las funciones definidas por $f(x)=\frac{(x+1)(x-2)}{x-2}$ y $g(x)=x+1$, en el dominio R-\{2\}. Explique ampliamente porqué estas funciones son iguales.

$$
\begin{aligned}
& f(x)=g(x) \\
& \frac{(x+1)(x-2)}{x-2}=x+1 \\
& x+1=x+1 \\
& \therefore \text { la tunción } f(x) \text { y la tunción } g(x) \text { son } \\
& \text { iguales y tiene su dominio en } R-\{2\}
\end{aligned}
$$

The results show that university students, when using the concept of function, in general, do not support their conclusions to communicate their processes in the resolution of items nor build justifications according to what is considered in criterion 3, that is, they do not provide solid reasons about their own conclusion. What they are trying to do is to identify and argue only whether a statement is true or false, depending on the context situation of the claim. What this entails is that the students cannot explain a mathematical rule, presenting little understanding of the concept of function. This implies that to have a high level of understanding, skills must be developed not only to recognise aspects of the function such as its definition, its discrimination, or its application, but also to consider the ability to justify such aspects.

\section{CONCLUSION}

In this work, the analysis of the understanding of thirty-six university students about the concept of function was presented when they solved six items that alluded to the mentioned concept. For the analysis, the reference framework of Albert and Kim (2015) was used, which permitted designing the 
items and getting to know the abilities of justification and argumentation of the students.

In the written productions of the students, we realised that most of them presented a low understanding in the category of ability to justify, which means that they did not provide solid reasons to justify their own conclusions. As in category three, understanding where a mathematical rule comes from, the majority of students once more presented a low understanding of the concept of function, as an evidence that they only demonstrate procedural skills or memorisation of the process, and that they do not manage to understand the use of a mathematical rule. Meanwhile, in the second category, understanding why a mathematical statement is true, it is evident that most of the students showed a medium understanding of the concept of function, for they emitted a correct truth value but their arguments did not validate their position regarding the statement.

Compared to what is mentioned by the Common Core State Standards for Mathematics (2010), we can conclude that university students do not present an understanding of the concept of function, since they do not have the ability to justify their mathematical processes in a suitable way, in contrast with their formative maturity. Therefore, to understand a mathematical concept you must not only have the procedural ability to develop an exercise, but you must have a combination of the three categories mentioned by Albert and Kim (2015). To this end, teachers must promote items that demand from students the need not only to develop an exercise in a procedural way, but also to understand, justify, and appropriate mathematical concepts, aiming at preparing them for their university and professional life.

On the other hand, according to the reasons presented by Prada, Hernández, and Ramírez (2014) and what was found in this research, we can confirm that the low understanding that most students manifest of the concept of function is due to the fact that they do not prioritise the understanding of the concept and its meanings, because they are limited to the algebraic manipulation of the concept, thus restricting their understanding, which is probably due to what was mentioned by Cuevas and Pluvinage (2017), who state that one of the problems in teaching the concept of function lies in how mathematics texts characterise it, as a formal and an unapplied object. 
It should be noted that today, we are in the modern period of the development of the concept of function as mentioned in Díaz (2013), however, although the concept is a fundamental part of the development of the life of every person, it is evident that university students have not been able to understand so as to communicate and interact in an assertive way in society, despite the fact that, in their previous educational levels, they have worked with the concept of function. For this reason, we suggest that teachers of both high school education and university encourage in their students the ability to justify their mathematical arguments and that they deepen the teaching of the concept of function, more from the conceptual than from the procedural perspective. What is sought is that the student understands where the mathematical rules embedded in the concept come from, how to use them, and how to be able to argue their usefulness.

In relation to one of the main purposes of the frame of reference, particularly the design of measurement tasks that make it possible to know the student's mathematical learning, evidence was shown of the design of the items, which were validated by users and experts, therefore, allowing to know the level of understanding in which university students are in relation to the concept of function.

\section{DECLARATION OF CONTRIBUTIONS OF THE AUTHORS}

FMRV conceived the idea presented. FMRV and JAAP developed the theory. JAAP adapted the methodology for the research, developed the activities, and collected the data. FMRV and JAAP analysed the data. All the authors actively participated in the discussion of the results, reviewed, and approved the final version of the paper.

\section{DATA AVAILABILITY DECLARATION}

The data supporting the results of this study will be made available by the corresponding author, [FMRV], upon reasonable request. 


\section{REFERENCES}

Albert, L. \& Kim, R. (2015). Applying CCSSM Definition of Understanding to Assess Students Mathematical Learning. In: Assessment to Enhance Teaching and Learning (pp. 233-246). National Council of Teachers of Mathematics.

Amaya, T. \& Sgreccia, N. (2014). Dificultades de los estudiantes de once grado al hacer transformaciones de representaciones de una función. Épsilon: Revista de la Sociedad Andaluza de Educación Matemática "Thales", 31(88), 21-38. https://thales.cica.es/epsilon/sites/thales.cica.es.epsilon/files/\%5Bfield volumen-formatted\%5D/epsilon88 2.pdf

Amaya, T., Pino-Fan, L. \& Medina R. (2016). Evaluación del conocimiento de futuros profesores de matemáticas sobre las transformaciones de las representaciones de una función. Educación matemática, 28(3), 111-144. https://doi.org/10.24844/EM2803.05

Arizmendi, H., Carrillo, A. \& Lara. M. Cálculo. Primer curso nivel superior. Addison-Wesley Iberoamericana.

Arnon, I., Cottril, J., Dubinsky, E., Oktaç, A., Roa, S., Trigueros, M. \& Weller, K. (2014). APOS Theory. A Framework for Research and Curriculum Development in Mathematics Education. Springer.

Bardini, C., Pierce, R., Vincen, J. \& King, D. (2014). Undergraduate mathematics students' understanding of the concept of function. IndoMS-JME, 5(2), 85-107. https://files.eric.ed.gov/fulltext/EJ1079527.pdf

Common Core State Standards for Mathematics (2010). National Governors Association Center for Best Practices. Council of Chief State School Officer. http://www.corestandards.org/wpcontent/uploads/Math_Standards.pdf

Cuevas, C. \& Pluvinage, F. (2017). Revisitando la noción de función real. El cálculo y su enseñanza, 8, 19-35. https://recacym.org/index.php/recacym/article/view/43/25

Delgado, M. L., Codes, M., Monterrubio, M. C. \& González, M. T. (2014). El concepto de serie numérica. Un estudio a través del modelo de Pirie y 
Kieren centrado en el mecanismo "folding back". Avances de Investigación en Educación Matemática, 6, 25-44.

https://doi.org/10.35763/aiem.v1i6.85

Díaz, J. (2013). El concepto de función: ideas pedagógicas a partir de su historia e investigaciones. El Cálculo y su enseñanza, 4, 13-26. https://mattec.matedu.cinvestav.mx/el calculo/data/docs/Diaz.a535a5 fbaf7a54a6250cf5a0bf132fda.pdf

Crespo, C. \& Ponteville, C. (2003). El concepto de función: su comprensión y análisis. Acta Latinoamericana de Matemática Educativa, 16(1), 235241.

Díaz, M., Haye, E., Montenegro., F. \& Córdoba, L. (2015). Dificultades de los estudiantes para articular representaciones gráficas y algebraicas de funciones lineales y cuadráticas. Unión: Revista Iberoamericana de Educación Matemática, 41, 20-38. http://www.fisem.org/www/union/revistas/2015/41/Artigo1.pdf

Dreyfus, T. \& Eisenberg, T. (1982). Intuitive Functional Concepts: A Baseline Study on Intuitions. Journal for Reseach in Mathematics Education, 13(5). 360-380.

Farfán, R. \& García, M. (2005). El concepto de Función: Un breve recorrido epistemológico. Acta Latinoamericana de Matemática Educativa, 18, 489-494.

Figueiredo, C. \& Contreras, L. (2013). A função quadrática: variação, transparência e duas tipologias de exemplos. Avances de Investigación en Educación Matemática, 3, 45-68. https://doi.org/10.35763/aiem.v0i3.62

Flores, J., Neira, V., Carrillo, F. \& Peñaloza, T. (2019). Funciones reales de variable real: mediación de la calculadora científica. Acta Latinoamericana de Matemática Educativa, 32 (2), 684-692. https://www.clame.org.mx/documentos/alme32_2.pdf

Hiebert, J. \& Carpenter, T. P. (1992). Learning and Teaching with Understanding. In: Handbook of Research on Mathematics Teaching and Learning (pp. 65-97). Macmillan. 
Kastberg, S. E. (2002). Understanding Mathematical Concepts: The Case of the Logarithmic Function. The University of Georgia.

Michener, E. R. (1978). Understanding understanding Mathematics. Cognitive Science, 2, 361-383. https://doi:10.1207/s15516709cog0204_3

National Governors Association Center for Best Practices and Council of Chief School Officers (NGA Center and CCSSO). (2010). Common Core State Standards for Mathematics. NGA Center and CCSSO.

National Council of Teachers of Mathematics. (2000). Principles and Standards for School Mathematics. NCTM.

Nickerson, R. S. (1985). Understanding Understanding. American Journal of Education 93(2), 201-239.

Ortega, T. \& Pecharromán, C. (2014). Errores en el aprendizaje de las propiedades globales de las funciones. Revista de Investigación en Educación, 12(2), 209-221. http://reined.webs.uvigo.es/index.php/reined/article/view/258/305

Pino-Fan, L. R., Parra-Urrea, Y. E. \& Castro-Gordillo, W. F. (2019). Significados de la función pretendidos por el currículo de matemáticas chileno. Revista Internacional de Investigación en Educación, 11(23), 201-220. https://doi.org/10.11144/Javeriana.m1123.sfpc

Pirie, S. \& Kieren, T. (1994). Growth in mathematical understading: how can we characterise it and how can we represent it? Educational Studies in Mathematics, 26, 165-190. https://doi.org/10.1007/BF01273662

Prada, R., Hernández, C. \& Ramírez, P. (2014). Comprensión del concepto de función en los primeros cursos de educación superior. El Cálculo y su Enseñanza, 6(6), 29-44.

Schoenfeld, A. H. (2007). What is mathematical proficiency and how can it be assessed? In: Assessing Mathematical Proficiency (pp. 59-74). Cambridge University Press.

Sfard, A. (1989). Transition from operational to structural conception: The notion of function revisited. In: Proceedings of the Thirteenth 
International Conference for the Psychology of Mathematics Education, 3, 151-158. G.R Didactique, CNRS.

Sierpinska, A. (1990). Some Remarks on Understanding in Mathematics. For the Learning of Mathematics, 10(3), 24-36.

Sierpinska, A. (1992). On understanding the notion of function. In: The concept of function: Aspects of epistemology and pedagogy. Mathematical Association of America.

Skemp, R. (1976). Relational Understanding and Instrumental Understanding. Mathematics Teaching, 77, 20-26.

Skemp, R. (1980). Psicología del aprendizaje de las Matemáticas. Ediciones Morata S.A.

Secretaria de Educación Pública. (2011). Programa de estudio 2011. Guía para el Maestro. Educación Básica. Secundaria. Matemáticas. SEP.

Serrano, W. (2007). Concepciones de los estudiantes sobre la inyectividad, sobreyectividad de la función cuadrática y sobre la gráfica de H: R$\{0\} \rightarrow \mathrm{R}$ definida por $\mathrm{h}(\mathrm{x})=\operatorname{sen} \mathrm{x} / \mathrm{x}$. Sapiens: revista universitaria de investigación, 8(2), 169-186.

https://www.redalyc.org/articulo.oa?id=41080211

Silva, L. \& Kaiber, C. (2013). Reflexões sobre o ensino de funções sob a perspectiva do enfoque ontossemiótico. Educação matemática em revista, 14(2), 27-36.

Vinner, S. (1983). Concept definition, concept image and the notion of function. The International Journal of Mathematical Education in Science and Technology, 14, 293-305.

Vinner, S. \& Dreyfus, T. (1989). Images and Definitions for the Concept of Function. Journal for Research in Mathematics Education, 20(4), 356-366.

Watson, A. \& Harel, G. (2013). The role of Teacher's Knowledge of Functions in their teaching: a conceptual approach with illustrations from two cases. Canadian Journal of Science Mathematics and Technology Education, 13(2), pp. 154-158. http://dx.doi.org/10.1080/14926156.2013.784826 
Wilkerson-Jerde, M. H. \& Wilensky, U. J. (2011). How do mathematicians learn math?: resources and acts for constructing and understanding mathematic. Educational Studies in Mathematics, 78, 21-43. https://doi.org/10.1007/s10649-011-9306-5

\section{Annex. Test of items designed and applied to students.}

\section{ITEMS}

Let $\Re$ be the set of real numbers and consider the functions of a subset of $\Re$ in $\Re$.

1. In a graphical representation, the criterion of the vertical line helps us determine whether it corresponds to the representation of a function. Explain in full why it is sufficient to use this criterion to validate this statement.

2. Consider the following statement: "a child's growth can be modelled by a real function of a real variable." The above statement is true or false. Fully justify your answer.

3. In the following graphs, determine which represent a real function of a real variable. Explain in full why. 


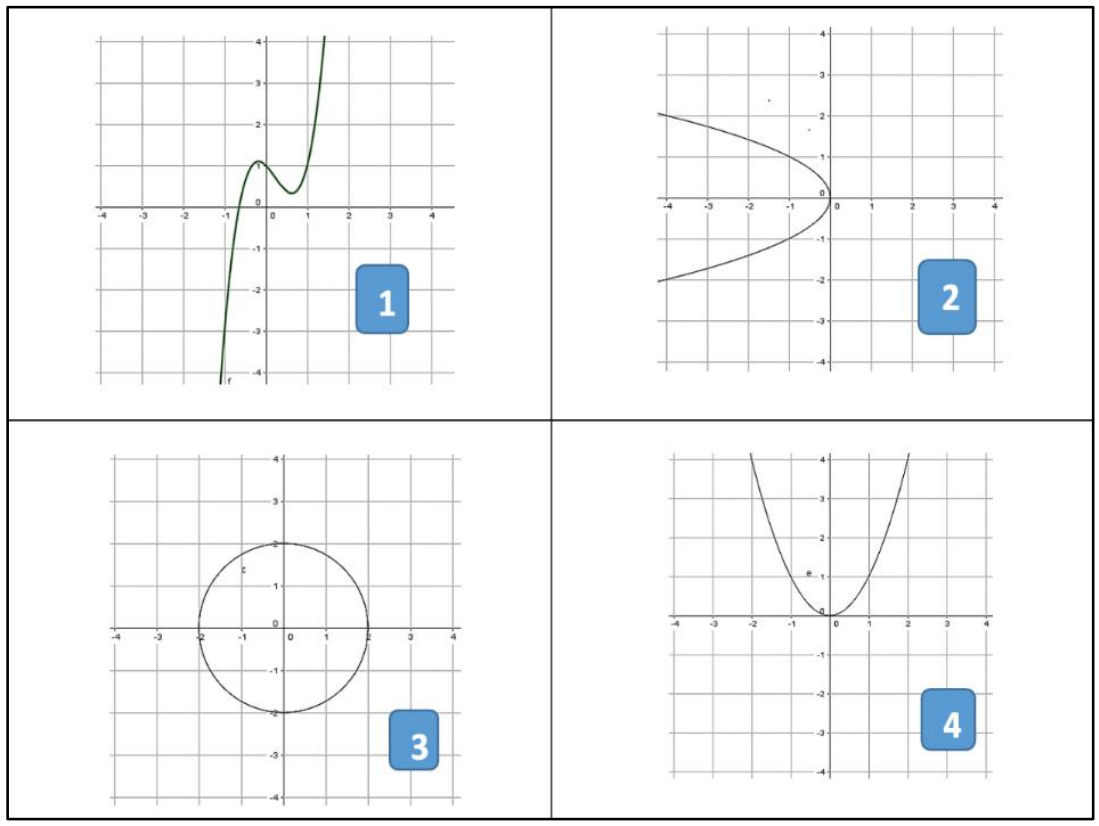

4. Consider the following graphical representations of real domain functions with real variable and classify them into different groups according to their characteristics. Explain your answer in full. 


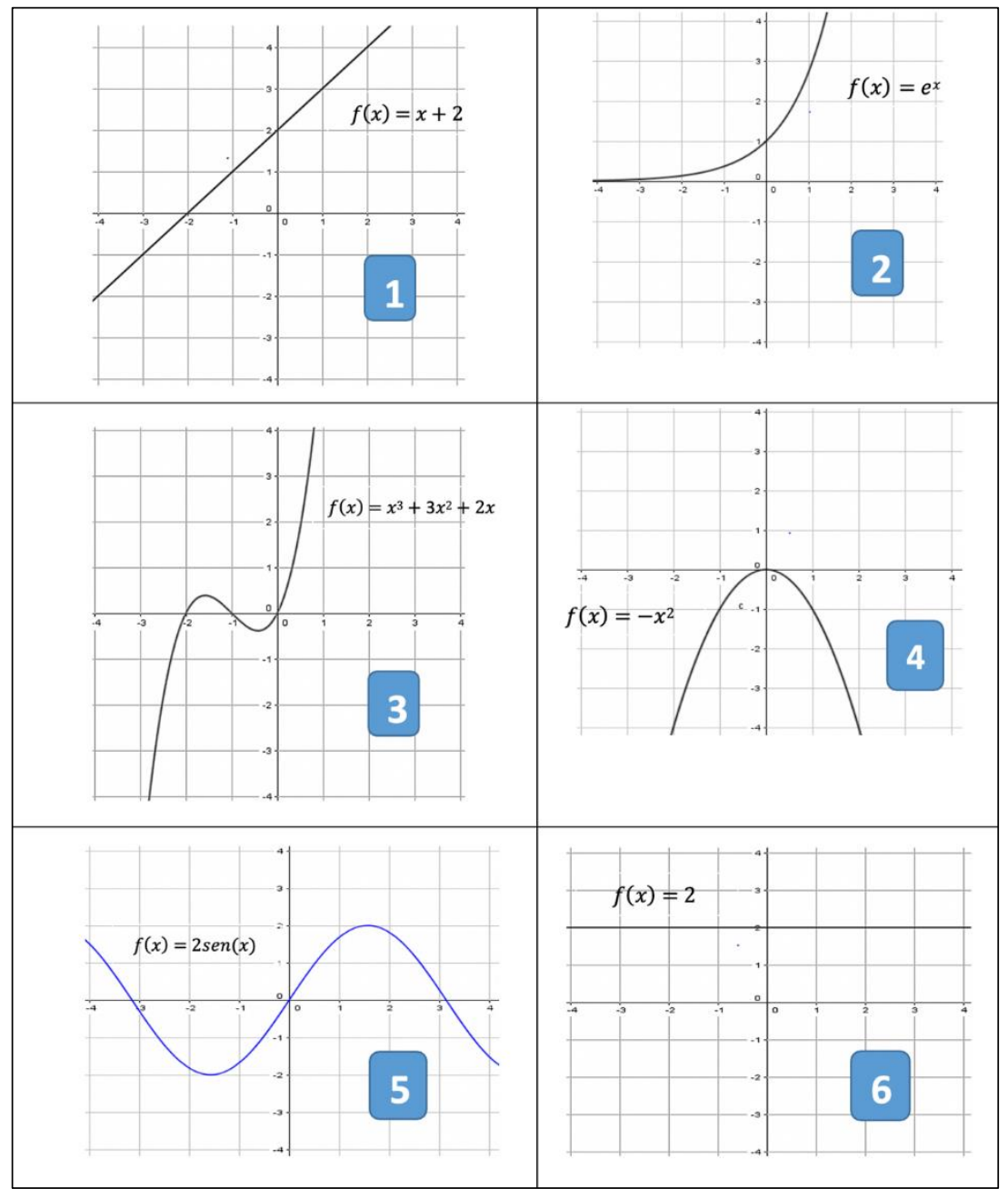

5. The following representations are associated with the same real function of a real variable. Explain in full why this statement is true. 


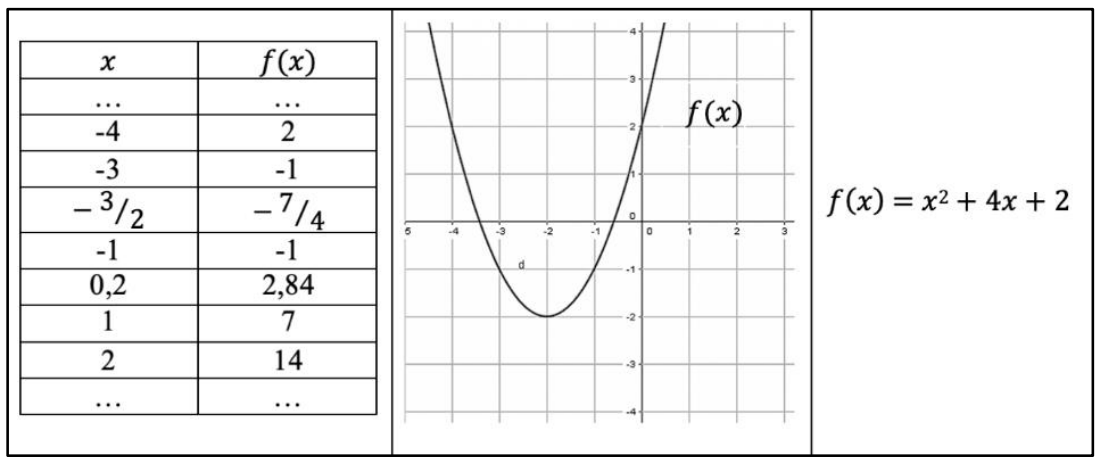

6. Consider the functions defined by $\mathrm{fx}=(\mathrm{x}+1)(\mathrm{x}-2) \mathrm{x}-2 \quad f(x)=$ $\frac{(x+1)(x-2)}{x-2}$ and $\mathrm{gx}=\mathrm{x}+1 g(x)=x+1$, in the domain $\mathrm{R}-\{2\}$. Explain in full why these functions are equal. 
